\title{
Corrigendum to "Genome-Wide Identification of Long Noncoding RNAs in Human Intervertebral Disc Degeneration by RNA Sequencing”
}

\author{
Bo Zhao, ${ }^{1}$ Minjuan Lu, ${ }^{2}$ Dong Wang, ${ }^{1}$ Haopeng Li, ${ }^{1}$ and Xijing He $\mathbb{D}^{1}$ \\ ${ }^{1}$ Department of Orthopaedic Surgery, The Second Affiliated Hospital of Medical College, Xian Jiaotong University, Xian 710004, China \\ ${ }^{2}$ Department of Respiratory Medicine, Baoji People’s Hospital, Baoji 721000, China \\ Correspondence should be addressed to Xijing He; xijinghe@126.com
}

Received 14 January 2019; Accepted 16 January 2019; Published 26 September 2019

Copyright $\odot 2019$ Bo Zhao et al. This is an open access article distributed under the Creative Commons Attribution License, which permits unrestricted use, distribution, and reproduction in any medium, provided the original work is properly cited.

In the article titled "Genome-Wide Identification of Long Noncoding RNAs in Human Intervertebral Disc Degeneration by RNA Sequencing" [1], there was a missing grant number. Thus, the Acknowledgments section should be updated as follows:

This study was supported by the grants from the National Health and Family Planning Commission (Grant no. 2011-1) and ShaanXi Natural Foundation (Grant no. 2016JM 8136).

\section{References}

[1] B. Zhao, M. Lu, D. Wang, H. Li, and X. He, "Genome-wide identification of long noncoding RNAs in human intervertebral disc degeneration by RNA sequencing," BioMed Research International, vol. 2016, Article ID 3684875, 8 pages, 2016. 


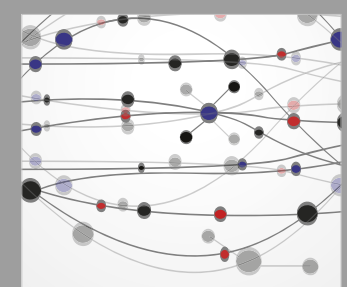

The Scientific World Journal
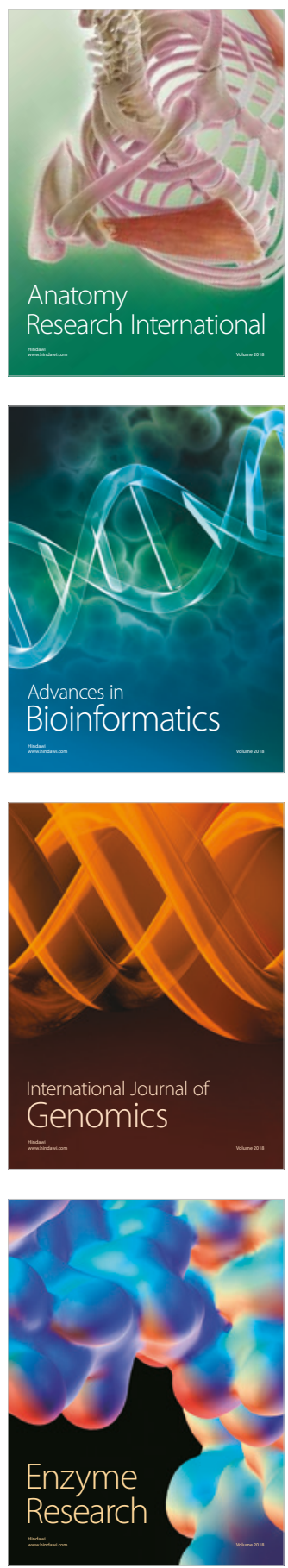
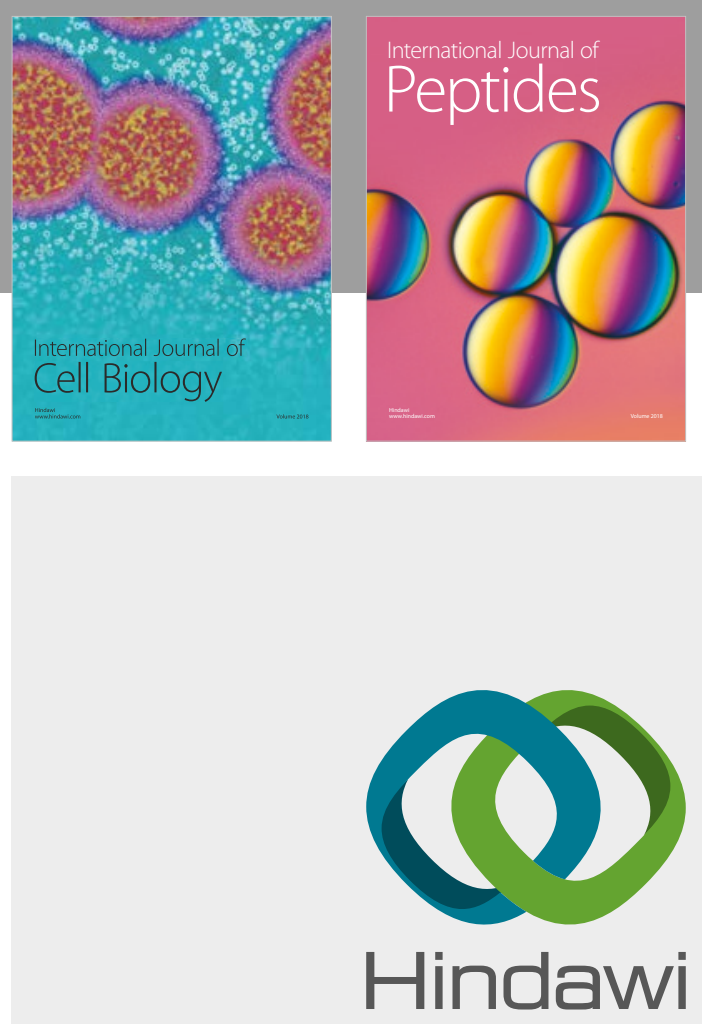

Submit your manuscripts at

www.hindawi.com
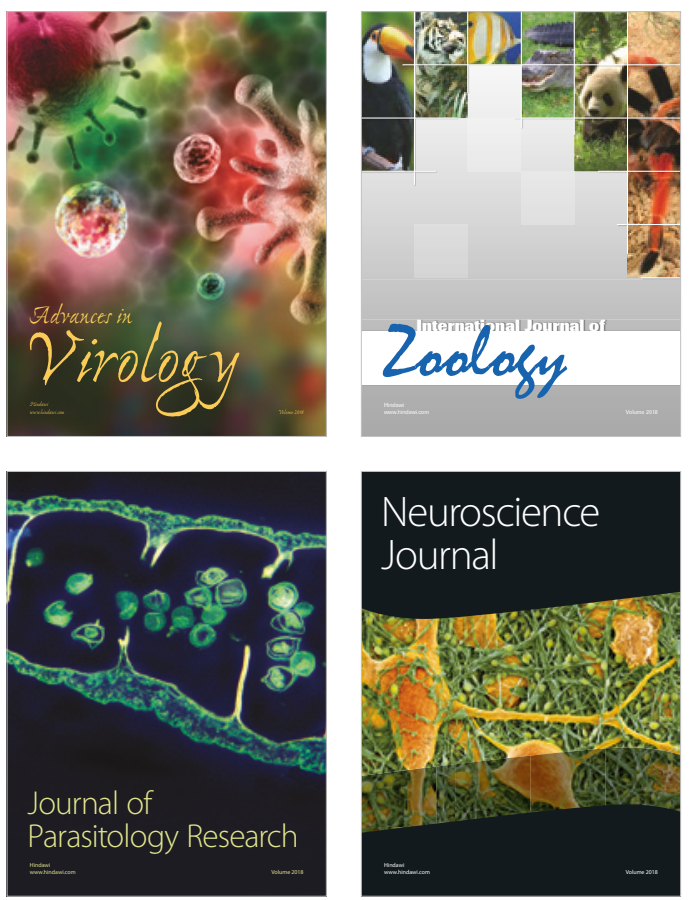
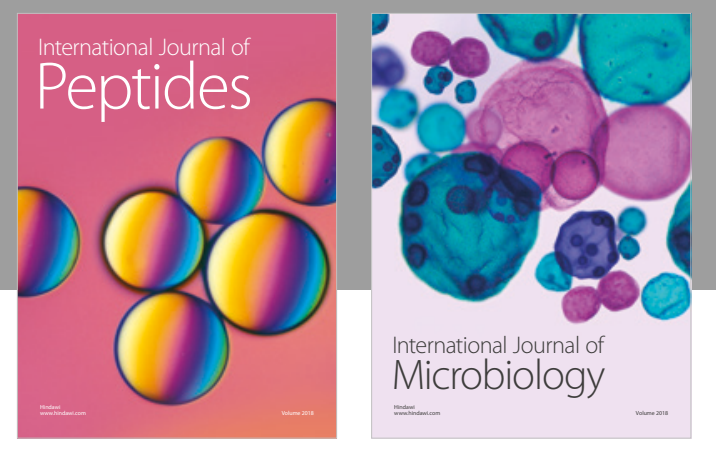

nternational Journal of Microbiology
Journal of
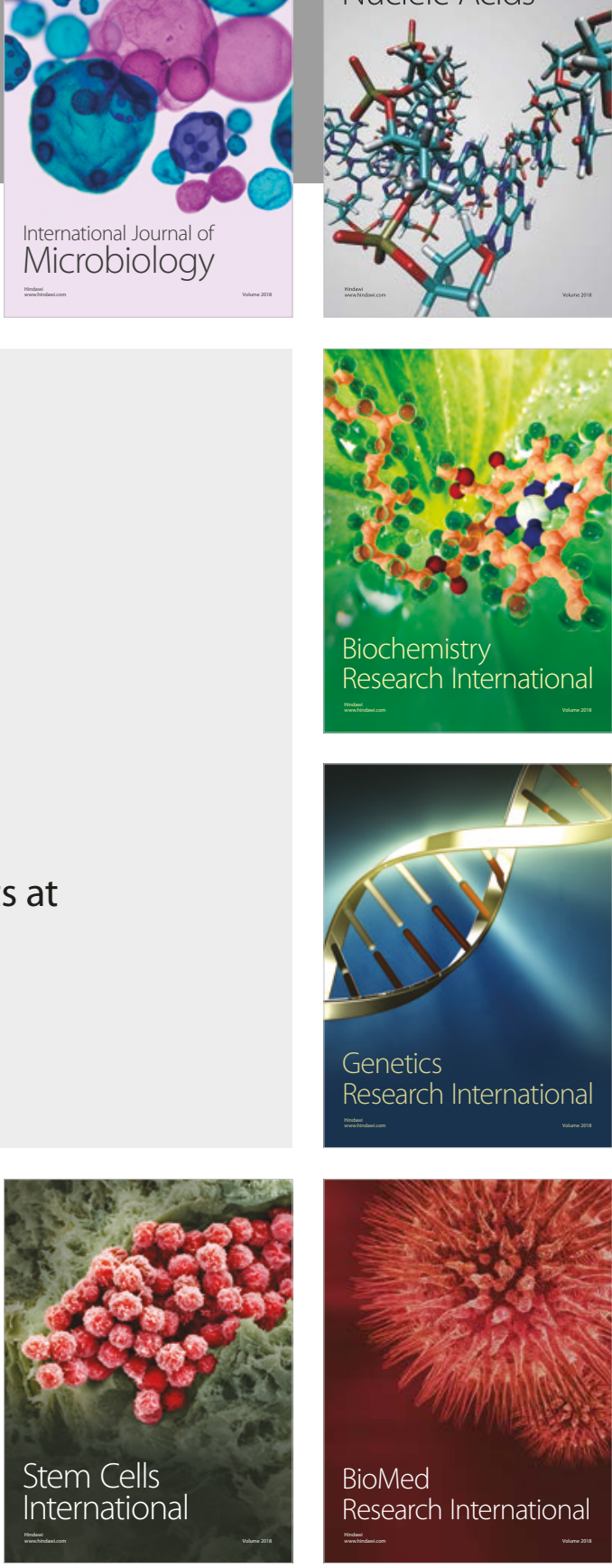
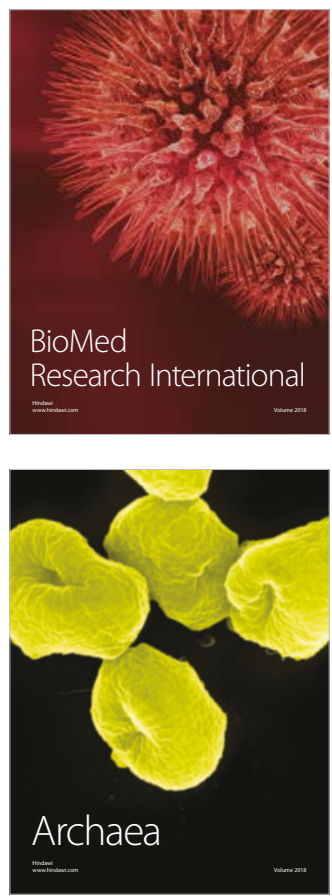